\title{
Recent flood event in Kaziranga National Park, Assam, India as assessed using remote sensing data
}

The Brahmaputra basin covers a geographical area of $580,000 \mathrm{~km}^{2}$, spreading over China, India, Bangladesh and Bhutan. India is the middle riparian country between China and Bangladesh on the Brahmaputra river which originates from the Angsi glacier in Tibet ${ }^{1}$. The catchment of the Brahmaputra within India spreads across the states of Arunachal Pradesh, Assam, Meghalaya, West Bengal, Nagaland and Sikkim. Flooding is a regular phenomenon in the lower catchment of the Brahmaputra.

This study focusses on the recent flood event (2017) in Kaziranga National Park (KNP), Assam (Figure 1). The park incorporates parts of the Brahmaputra and areas falling in Sonitpur, Golaghat and Nagaon districts (Figure 1). The Park is popular for great Indian one-horned rhinoceros (Rhinoceros unicornis). However, other animals such as elephants, tigers, wild buffaloes, ungulates, wild boars, etc. are also found in the park ${ }^{2}$. In 1985, the United Nations Educational, Scientific and Cultural Organization (UNESCO) declared KNP as a World Heritage Site for its unique natural environment. The Brahmaputra, along with its tributaries and distributaries, causes floods almost every year in Assam, resulting in the loss of human lives, livestock, and wildlife besides damage to property and infrastructure. KNP is the most flood-affected National Park in Assam. Around $74 \%$ of the area of the park (excluding the river and other water bodies) is grassland, which is the most favourable as natural habitat for rhinos and other animals. Hence, flood monitoring and assessment of loss in a biodiversity-rich area like KNP is a necessity using repetitive coverage of satellite data.

Satellite remote sensing has long been used as an essential tool for flood assessment and as complementary information for flood modelling and forecasting. One of the advantages of the remote sensing data is that they can provide information on large area in near real-time. Moreover, many of these datasets are freely available in the public domain. The main objective of the present study was to use freely available remote sensing dataset to assess recent flood situation (2017) of KNP.

We used three datasets, viz. SARAL/ ALtiKa (a radar altimeter), Landsat 8 OLI (Operational Land Imager) and allweather Sentinel-1 satellite operating in the C-band. Land-use and land-cover map for KNP was prepared using Landsat 8 OLI (Figure 2). Pre-flood Sentinel data of 25 February 2017 and post flood data of 12 August 2017 were used to map different levels of inundation categories in KNP (Figure 3). The water levels of the Brahmaputra were measured from radar altimeter of SARAL/ALtiKa, a joint mission of Indian Space Research Organisation (ISRO) and Centre National d'Études Spatiales (CNES). These two datasets were chosen such that one represented lean season and the other
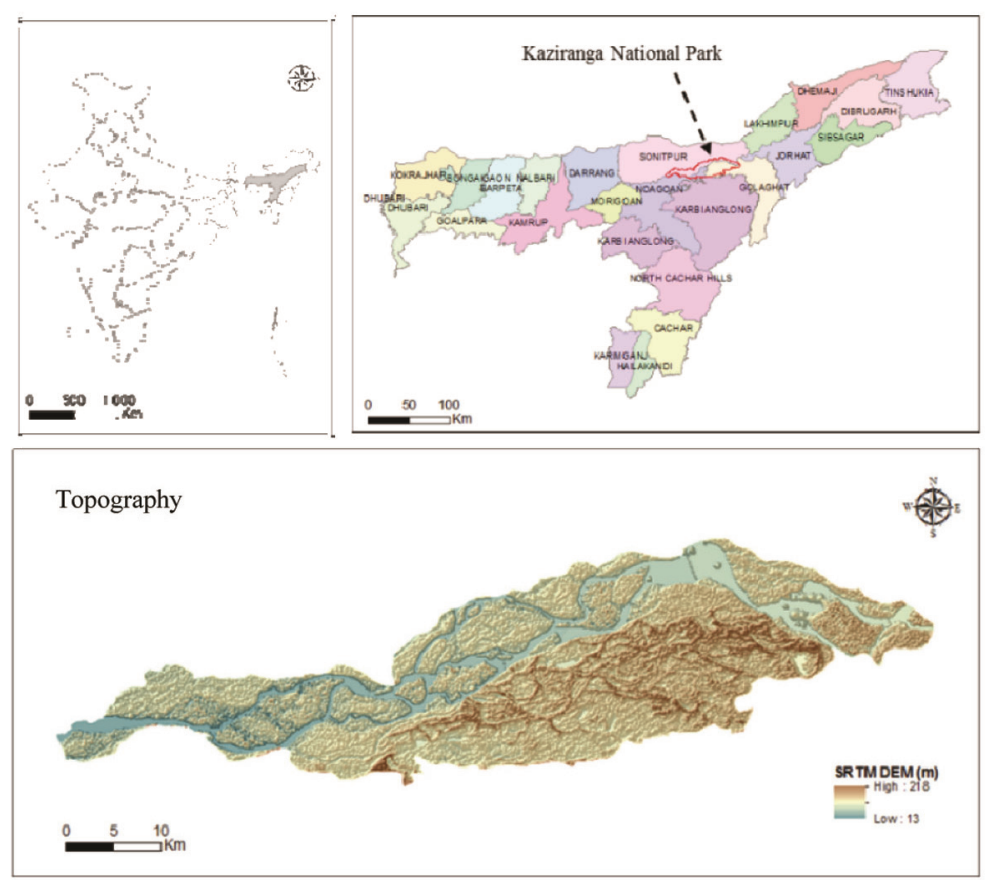

Figure 1. Map of Kaziranga National Park (KNP), Assam, India.

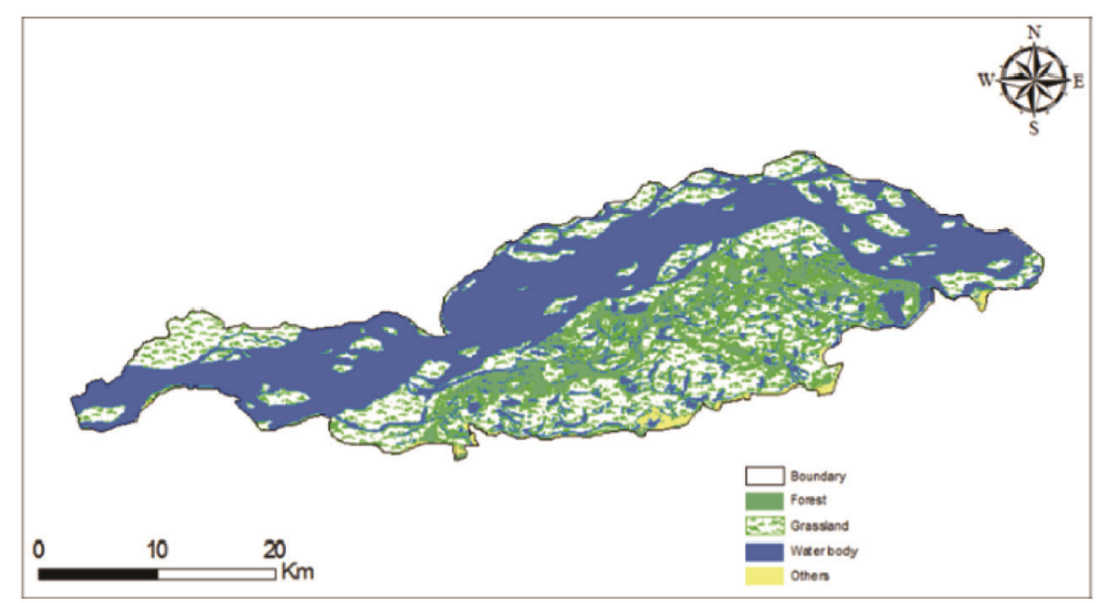

Figure 2. Land-use/land-cover of KNP. 


\section{SCIENTIFIC CORRESPONDENCE}


Deep water $\square$ Slathow water $\quad$ Non-twater

Figure 3. Pre- and post-flood map (2017).

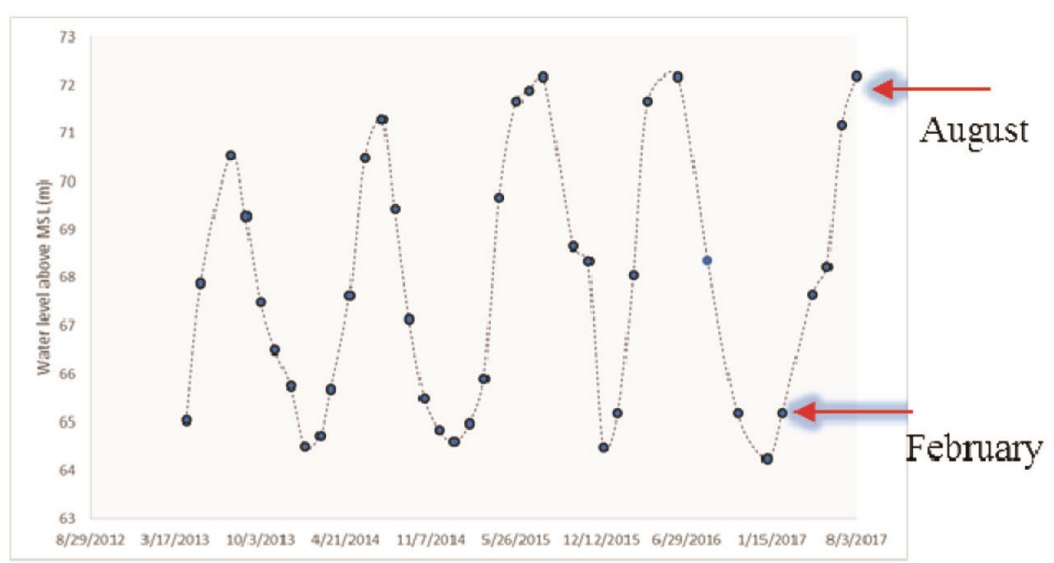

Figure 4. Water-level variation of Brahmaputra river in KNP.

exemplified flooding season. Sentinel 1A is a polar orbiting day-and-night satellite that works in the C-band range. Therefore, Sentinel dataset is most suitable to assess flooding condition, specifically under cloud-cover condition.

The flood situation in Assam became very critical during the second week of
August 2017, affecting several districts of the state. Flood has affected the expanse of the Brahmaputra river, which has increased by 3-5 times in some parts during this period (February to August 2017; Figure 3). Around $67 \%$ of grassland was inundated on 12 August 2017 (Figures 2 and 3). SARAL/AltiKa data were processed using the ICE-1 retracking method. The water-level variation provides information about the status of inundation of the flooded $\operatorname{area}^{3}$. The water level increased by $\sim 7 \mathrm{~m}$ from February to August 2017 (Figure 4).

The present study has successfully demonstrated the use of freely available data for a quick assessment of the recent flood of 2017 affecting KNP. A detailed study can be done to assess the flood vulnerability of KNP, specifically considering the ecological importance of this Park.

1. CWC and NRSC. (2014, March); http:// www.india-wris.nrsc.gov.in/Publications/ BasinReports/Brahamaputra\%20Basin.pdf (last accessed on 21 August 2017).

2. Kushwaha, S. P. S. et al., Project report, IIRS/FED/Kaziranga/36/8026/2008.

3. Ghosh, S., Nandy, S. and Senthil Kumar, A., Curr. Sci., 2016, 111(9), 1450-1451.

Received 28 August 2017; revised accepted 14 June 2018

\section{SURAJIT GHOSH* RAJ KUMAR UtTaRa PANDEY \\ PARUL SRIVASTAVA SWAPAN MEHRA}

IORA Ecological Solutions Pvt Ltd, $225 B, F F$, Indraprastha, Gyanamandir Complex,

Lado Sarai Village,

New Delhi 110 030, India

*For correspondence.

e-mail: surajitghosh.ind@gmail.com

\section{Non-tectonic signals in tectonic geodesy}

Earth's gravitational field, its shape and orientation in the space are the "three pillars of geodesy ${ }^{1,2}$. In recent times, geodesy has emerged as an interdisciplinary domain in geophysics, which includes tectonics, internal structure of the earth, seismology, hydrology, glaciology, oceanography, meteorology, atmospheric physics, climate science, etc. ${ }^{1}$. In fact, it has found several applications in earth sciences that a new subject 'tectonic geodesy' has evolved, which specifically deals with the application of geodetic techniques in understanding tectonic processes by estimating surface velocity 